24

\title{
Enhancing traditional university science teaching using the World Wide Web
}

\author{
Michael W. Nott \\ Matthew D. Riddle \\ Jon M. Pearce \\ The University of Melbourne \\ Parkville, Victoria \\ Australia
}

\begin{abstract}
The University of Melbourne has a history of traditional teaching modes with a strong emphasis on bridging discipline based research and teaching. A major strength of the World Wide Web at this institution is its ability to allow the mounting of high quality specialized graduate teaching programs, characteristic of a research based university. Other advantages of the Web for science teaching include: multiplatform access, nonreliance on specified classrooms with consequent saving in teaching space, off-campus delivery, hypertext facilities with structured guidance, ability to offer students choice of resources and student feedback using 'fill-out forms'.
\end{abstract}

Main conference themes: distance learning, methodologies

Educational areas: higher education

Study topics: science/engineering

Secondary keywords: computer assisted instruction, future developments, hypermedia, networks, teaching methods, user interface 


\section{INTRODUCTION}

In a time when tertiary education in Australia is undergoing rapid change, the emergence of the World Wide Web as a readily accessible resource has encouraged many of us to re-examine the way we present courses. This paper begins by considering the place of the Web in multimedia based teaching and, in particular, the way in which groups within a large Australian university are addressing the use of such a resource. The latter part of the paper looks at some issues specific to science teaching and ideas being explored in this area.

\section{THE WORLD WIDE WEB IN A MULTIMEDIA SETTING}

Developments in computer aided learning, particularly through multimedia, have grown markedly in Australian universities over the last five years. In the University of Melbourne in 1994 there were around 70 identifiable groups developing and using computer aided teaching programs. Reasons for this increase in activity include:

- new developments in hardware and software;

- an increased emphasis on the importance of quality in teaching in the university;

- an increased intake of students so that staff teaching loads and traditional teaching spaces have become stressed;

- generous internal and external grant systems which reward innovation in teaching.

\section{Present use of multimedia}

At the University of Melbourne one priority for implementation of multimedia focuses on lecture theatres with the lecture continuing to be the major delivery platform for almost all undergraduate teaching programs. Forty lecture theatres have been upgraded to allow high quality video, audio and computer projection during regular lectures. But lecture theatre upgrades by no means provide the total answer for delivery of multimedia. Chemistry and Biology provide other examples: in the School of Chemistry an increase in the first-year student intake from 1200 (in 1992) to 1500 (in 1994) led to the situation where the practical laboratories were unable to cope. Chemistry in response built a 42 workstation multimedia classroom to present programs which complemented and augmented practical class teaching and at the same time allayed the overload on the laboratories. Biology, another first year subject with a large student input, is following suit with a 30 workstation facility in 1995 and a duplicate system in 1996. 
Other faculties are installing facilities similar to those in Chemistry and Biology. But in spite of this growth in the number of multimedia classrooms only a small proportion of teaching hours (which typically total about 26 per week for a first year student in Science) can be accommodated in these new multimedia classrooms. The 42 workstation facility in Chemistry when used for 37.5 hours per week, can for example serve each of the 1500 first-year students for only one hour. Putting the appropriateness of multimedia aside two factors appear to limit a significant increase in delivery of multimedia based programs: cost and space.

\section{The problems of cost and space}

The cost of providing new multimedia classrooms is not the most important factor for further multimedia implementation. Indeed the cost per student-hour to provide multimedia programs in such settings can be as little as $\$ \mathrm{~A} 3.00$ which compares favourably with the cost of traditional tutorials and which is considerably cheaper than the cost of science practical classes.

The limiting factor in providing more multimedia based classes is in fact space- there just being not enough of it on campus for sufficient workstations. Indeed we predict that, unless alternatives to the provision of campus based computer workstations are found, development of multimedia as a way of teaching will be severely hampered. Already at the University of Melbourne we appear to be reaching a nexus. Academics who on the basis of a demonstrable success in multimedia for teaching in first year, wish to use multimedia to enhance teaching in second and third year are faced with an implementation problem - having to hunt outside their department for sufficient high quality computers to mount their teaching programs.

\section{THE WORLD WIDE WEB}

Given that on-campus computer facilities will be unable to meet the future demand for interactive multimedia teaching and learning, we must explore other ways of delivering multimedia. Software such as Mosaic running on the World Wide Web may provide the answer. Using the Web we can distribute multimedia programs through Ethernet to workstations right around the campus (and potentially beyond). This provides maximum flexibility for delivery and in areas such as the library the opportunity for students to access programs at all hours.

We can also provide points into which students can plug their own small portable computers though at Melbourne most students do not yet have powerful enough machines to run the typically high end multimedia programs 
developed by staff-however we anticipate that this situation will be rectified within a few years. Ultimately we may provide dial-up access for students who wish to take their multimedia classes off campus. In order to provide this networked approach we are exploring the strengths and deficiencies of HyperText Markup Language (HTML).

\section{Web software}

HyperText Markup Language is the language used to create hypertext which allows for linking of documents on the Web viewed through client software such as Mosaic, MacWeb, WinWeb or Cello for Windows. Accessing information this way encourages a form of delivery which suits many teachers: a lesson presented in the typical linear lecture style format with the potential for branching from previously defined words in the text using Hyperlinks. The text which constitutes the basic lesson, resides on the so-called 'Home Page'. The key words on the home page may link to other parts of the same document, to other documents on the same computer or to documents on any other computer on the Web. Documents may include text, graphics, video or audio.

\section{Strengths of the Web}

The clear facility which a hypertext environment offers education, is its access to vast amounts of information distributed globally. Such a medium can impose some much needed structure onto otherwise disparate sets of resources. For science teaching this also encourages students to move freely between learning and selfguided research. At The University of Melbourne a critical aim of the science undergraduate course is the development of research skills in students. Within the Web students can move easily from an interactive tutorial developed locally to, for example, a database containing up to date environmental data or results from the on-going Human Genome Project. The Web therefore offers a means by which we can integrate teaching modules with the rich source of online information that is available through the Internet.

Exploration of these resources is via public domain software and is not restricted to any particular computer setting: computer lab, information kiosk, science lab or notebook are all possible. Students can use Macintosh, Windows, or UNIX X-Windows environments. The Web also allows dial-up access via standard UNIX or VAX accounts using hypertext only clients, such as lynx, for example for review of teaching materials and lecture notes from home.

The nature of the resources one might give students access to via the Web is similarly diverse. They might be text, graphics, video, animations, sound, sets of numeric data, up to date on-line data, research publications and so on. If many different possibilities offer students the desired learning experience, 
then students can be given a choice and in so doing their active control over what or how they learn is increased. Such choices might range from sets of data to analyze in a spreadsheet to a variety of case studies to evaluate and report on.

Information on a Web server can be maintained centrally by the lecturer making management easy. The problems of packaging digital data on discs and $\mathrm{CDs}$, and then marketing and mailing, and the difficulties of version control and updates are minimized. The process becomes concentrated at a point where universities tend to excel: in the provision of rich teaching material content.

This reduction in the ratio of time and energy in delivering compared to preparing of lessons is particularly likely to appeal to many traditional universities which have not seriously considered distance education as their brief-rather choosing to concentrate on their strengths in research and oncampus teaching. The hope is that they might now become providers of high quality educational packages for the Web, as a painless offshoot of their intramural teaching. There should be less need to set up sophisticated marketing and advertising divisions. Indeed the lessons of an expert researcher/lecturer should be snapped up.

\section{Weaknesses of the Web}

It is always easy to be critical of or see flaws in new technologies in their infancies - before these have had time to be explored and evaluated. In the case of the World Wide Web we must be careful to separate criticisms of the Web as such from criticisms of client software to access the Web such as Mosaic, MacWeb, WinWeb or Cello. While both the Web and the software are still in their infancy, it is the software which tends to receive the criticisms since this is the interface through which we view the Web. However, the software is rapidly changing in response to user demands (educational users should put in their bid here-directly to the programmers via the Web!) whereas the concept of the Web itself and the technology of its implementation are more stable, yet nebulous.

Web client software is currently limited in several areas: the way it presents multimedia requiring separate 'helper applications' for movies, sound and some images, the restrictions it imposes on screen layout, the lack of simple programming facilities and the lack of sophistication in its presentation features.

A limitation of the concept of the Web shows when doing a back-of-theenvelope calculation of what the required data bandwidth might be in a few years time. The bandwidth required for a simple colour image is roughly two orders of magnitude greater than that required for a page of text. For a few seconds of low quality video it is yet another two orders of magnitude higher 
again. It is currently a hot topic to find ways of solving the bandwidth problem as our data superhighways are opened up to the masses.

\section{Lecture support material on the Web}

There is little point in using software like Mosaic for the presentation of a traditional text based lecture. Other software such as PowerPoint does this far better and offers the same advantages of being accessible to students after the lecture via a network connection. In any case experience has shown that students are tempted to dump out on paper the text from any on-line lectures - something much more efficiently done as a lecture handout.

However, if lecturers have been making use of multimedia resources in the lectures (pictures, animated diagrams, videos) then there is a place to make those resources accessible after the lecture. Students should be motivated to go looking for such access since these resources cannot be easily recorded in a student's notes during the lecture.

If a lecture is to be presented using Mosaic, the document should be well structured with the initial page maybe setting out a whole course as a series of lecture topics. Each topic could be hot-linked to a screen showing the main points of the lecture and these in turn linked to more minor points with links to the various resources where appropriate. Each screen might end with a button to return the student to the previous page in the hierarchy so as to minimize the chance of a student getting lost. Such a document could also be used in the presentation of the lectures and through the process of expanding topics using hyperlinks might help reinforce to students the overall structure of the lecture.

\section{Supporting resources for lectures}

Some lecturers are planning to use the Web in their teaching and also to provide additional Web resources for students who wish to follow up later. All computers at The University of Melbourne are networked and have software to access the Web, whether PC, Macintosh or UNIX. This provides students with a wide choice when it comes to trying to access a machine for this purpose.

This interaction need not be one way. The use of 'fill-out forms' allows a facility in which the student can return comments to the lecturer. Maybe a space on each screen into which a student could type a message that the notes were unclear or that the lecture needed further expansion on a particular point.

\section{Assigning follow-up work with student choice}

Many lecture courses involve students doing problem work or assignments of some kind. These can be attached to the lecture document and students directed to select one and submit it for assessment. The ease of adding extra 
links to a document makes it a simple task for the lecturer to offer numerous examples to choose from. A physics student might be offered several sets of experimental spreadsheet data from which to choose and carry out an analysis. A biology student might be presented with images of several plant crosssections to examine and identify. A meteorology student might be given a choice of current weather maps from various countries and be asked to explain local conditions. A chemistry student might be offered 3-D animations of various molecules and be asked to label and identify them.

In all cases students are making choices about when they learn and what they learn, and can be offered the opportunity to return comments to the lecturer or tutor. Not only can this take place away from the campus, but the whole package can be offered to students at other institutions without the traditional problems of advertising, marketing, packaging and distribution.

\section{PROJECTS AT THE UNIVERSITY OF MELBOURNE}

A number of projects is being initiated at the University of Melbourne to establish the value of the use of the Web in teaching. Preliminary formative evaluation of these projects is effected by encouraging feedback from the students via the document while they are using it.

\section{Physics practical class support}

Students in a subject such as physics often have difficulty in preparing for a laboratory class as they are unfamiliar with the equipment described in the notes and hence can make little sense of the instructions. This difficulty is being addressed by offering Web resources which complement a laboratory session. By putting laboratory notes on the Web and adding pictures of equipment, video clips of techniques and even sample data for analysis students will be better prepared on entering the laboratory and thus make better progress through it.

In contrast to this approach are the multimedia resources developed at the university to accompany a set of undergraduate pharmacology labs $[1,2]$. These resources comprize a HyperCard stack containing laboratory notes, simple introductory quizzes and video clips of laboratory techniques. These are all high quality produced with a finely crafted user interface. However, these were constructed by a multimedia programmer and any additions or modifications require the skills of such an expert. Web resources on the other hand can be compiled without programming skills and, most importantly, can be added to with minimal effort. One need not produce additional support materials for a set of labs all in one go: pictures, animations and video clips can be added as time permits. 


\section{Zoology practical class simulations}

A population dynamics course in second year Zoology is being piloted. The course is intrinsically rich in graphics and is centred around a population growth simulator. Previously we might deliver such a course using the strengths (and weaknesses) of HyperCard with $\mathrm{C}$ programming. The brief for the pilot is to design the course for delivery on the Web using its strengths to best advantage.

Physics Honours class delivery

A Web based pilot study of a highly specialized physics unit employing text, dynamic graphics and interaction with tutors (using 'fill-out forms') will be trialed on campus using the relatively high bandwidth afforded by the University's network in anticipation of access by modem or Internet by offcampus students.

\section{CONCLUSION}

We are just beginning to explore the potential offered by the World Wide Web. Many of our traditional ways of teaching and students' ways of learning will be challenged by this technology. We may find that it helps us to realize some of the long sought-after goals of a more open learning environment: 'open' in terms of content, location and methodology.

\section{REFERENCES}

1. Pearce, J. M., Riddle, M. D., and Nott, M. W. (1993) Science Laboratories, Computers and Multimedia: Opportunity for Change. Proceedings of the Xth Annual Conference of the Australian Society for Computers in Learning in Tertiary Education, University of New England, Lismore, pp. 444-453.

2. Nott, M. W., Williams, D. W. and Kemm, R. E. (1994) Designing for Change in Laboratory Teaching: Pharmacology and Physiology. Proceedings of IFIP WG 3.2 International Working Conference, Melbourne (submitted). 